\title{
Chronology of cardiac dysfunction after permanent pacemaker implantation: an observational 2 year prospective study in North India
}

Harshit Gupta', Hakim Irfan Showkat² ${ }^{2}$, Naved Aslam', Rohit Tandon', G. S. Wander', Shweta Gupta1, Sadaf Anwar ${ }^{3}$ and Mohd Maqbool Sohil ${ }^{4}$

\begin{abstract}
Background: The purpose of this study is to evaluate cardiac functions using transthoracic echocardiography, change in lead parameters and electrocardiogram (ECG) morphology in patients undergoing permanent pacemaker implantation over a follow-up period of 6 months.

Methods: This is a prospective study in patients undergoing permanent pacemaker implantation in a tertiary care hospital. Patients undergoing permanent pacemaker implantation were enrolled for up to one year and Echocardiographic parameters (by 2 blind operators) and ECG parameters were recorded at admission (within $24 \mathrm{~h}$ ), before discharge (within 7 days of pacemaker implantation), after 1 month ( \pm 7 days) and after 6 months ( \pm 7 days) of follow-up.

Results: A total of 96 patients (60.4\% males and $39.6 \%$ female, mean age 66.65 years) were implanted with permanent pacemaker. The mean QRS duration was $133.18 \mathrm{~ms}$ and increased significantly to 146.03 ms by 6 months despite septal lead placement in majority (92\%) of patients. The mean baseline ejection fraction of 51.47 decreased significantly to 47.83 by 6 months. Diastolic parameters like left atrial volume index, early to late diastolic transmitral flow velocity $(E / A)$ and early diastolic mitral annular tissue velocity $\left(E / e^{\prime}\right)$ showed a significant increase $(>5 \%)$ from baseline by the end of first week. By the end of first month, systolic dysfunction of RV sets in with significant (>5\%) change from baseline in parameters like Right ventricle myocardial performance index, transannular plane systolic excursion and right ventricle systolic excursion velocity (RVS').

Conclusion: We have observed that pacemaker recipients with baseline reduced left ventricle (LV) systolic functions perform significantly worse compared to those with baseline normal cardiac functions and had a higher rate of deterioration of LV function. RV dysfunction is the first abnormality that occurs, by 1 week followed by LV dysfunction which starts by 1 month and the diastolic dysfunctions precede the systolic dysfunction. QRS duration also showed a gradual increase despite septal lead placement in majority (92\%) and lead parameters showed no significant change over 6 months.
\end{abstract}

Keywords: Pacemaker, Echocardiography, RV dysfunction, LV dysfunction

*Correspondence: Docirfanshahi512@gmail.com

${ }^{2}$ Grecian Superspeciality Hospital, Mohali 110065 , India

Full list of author information is available at the end of the article

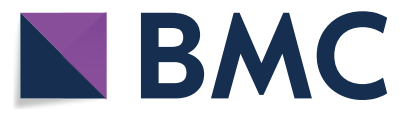

(c) The Author(s) 2021. This article is licensed under a Creative Commons Attribution 4.0 International License, which permits use, sharing, adaptation, distribution and reproduction in any medium or format, as long as you give appropriate credit to the original author(s) and the source, provide a link to the Creative Commons licence, and indicate if changes were made. The images or other third party material in this article are included in the article's Creative Commons licence, unless indicated otherwise in a credit line to the material. If material is not included in the article's Creative Commons licence and your intended use is not permitted by statutory regulation or exceeds the permitted use, you will need to obtain permission directly from the copyright holder. To view a copy of this licence, visit http://creativeco mmons.org/licenses/by/4.0/. 


\section{Background}

Permanent cardiac pacing is the most efficient treatment for patients with chronic high-degree atrio-ventricular (AV) block and symptomatic sick sinus syndrome (SSS). The right ventricular (RV) apex has been the preferred site for ventricular lead placement because of good pacing and sensing function,the ease of implantation and long-term stability of passive pacing leads [1]. Emerging clinical evidence has confirmed that RV pacing leads to abnormal ventricular activation and contraction that are associated with adverse long-term clinical outcomes [2, $3]$. More studies are needed to fully understand the beneficial and deleterious effects of RV pacing and better identify the patients who are at risk for its detrimental effects. However, the early prediction of myocardial dyssynchrony might provide opportunities to prevent further deterioration into advanced heart failure. With this background we planned this prospective study to identify the patients at high risk for deteriorating heart functions.

\section{Methods}

\section{Aims and objectives}

To assess the ventricular functions, QRS duration and pacemaker lead parameters over a period of 6 months in patients after permanent Pacemaker implantation.

\section{Study population}

This is a prospective study in patients undergoing permanent pacemaker implantation in a tertiary care hospital in North India. Patients undergoing permanent pacemaker implantation were enrolled for up to one year and Echocardiographic parameters and ECG parameters were recorded at admission (within $24 \mathrm{~h}$ ), before discharge (within 7 days of pacemaker implantation), after 1 month ( \pm 7 days) and after 6 months ( \pm 7 days) of follow-up. All patients eligible for permanent pacemaker implantation according to current guidelines were included.

We included patients over 18 years of age who needed permanent pacemaker according to indications of the ACC/AHA guidelines for implantation of a permanent pacemaker. We excluded patients participating in other studies or patients who cannot perform follow-up in the centre.

Particulars of all the study participants along with presenting complaints, detailed present, past, personal and family history were noted at admission. The indication of pacing, type of pacemaker (Single Chamber/ Dual Chamber), lead position (Apical/Septal), pacing mode (DDD or VVI) and the lead parameters were noted after pacemaker implantation. All the study participants underwent routine echocardiography (2 blind operators) and ECG at admission (within $24 \mathrm{~h}$ ), before discharge (within 7 days of procedure), after 1 month ( \pm 7 days) and 6 months ( \pm 7 days) of follow-up using a standardized protocol and required parameters were noted and recorded. Pacemaker Interrogation was done on followup of 1 month and 6 month and the lead parameters like resistance, voltage, sensitivity and pacing percentages were recorded. Cumulative per cent ventricular paced (Cum\%VP) was calculated by (1) finding, for each visit, the mean per cent ventricular paced over all visits up to and including that visit, weighted by the number of days between visits, and (2) using linear interpolation to determine the values for days between visits. Mean value of all these parameters was calculated at 0,1 week, 1 month and 6 month and a change of more than 5\% from the mean value of these parameters was regarded as practically significant change. The study was approved by the institutional review board, and all included subjects gave informed consent to participate in the registry.

\section{Statistical analysis}

Data were described in terms of range; mean \pm standard deviation $( \pm S D)$, median, frequencies (number of cases) and relative frequencies (percentages) as appropriate. Comparison of quantitative variables between the study groups was done using paired $t$ test for independent samples for parametric data. For comparing categorical data, Chi square $\left(Z^{2}\right)$ test was performed and exact test was used when the expected frequency is less than 5. A probability value ( $p$ value) less than 0.05 was considered statistically significant.

\section{Results}

A total of 128 patients received a conventional single- or dual-chamber pacemaker during this period and were assessed for eligibility. Among all pacemaker recipients, 28 did not meet the entry criteria and 4 patients had pacing percentage less than $85 \%$ and were excluded from analysis. Hence, the study population consisted of 96 patients (58 male, 60.4\%) with a mean age of $66 \pm 11$ years. Over the 6 month follow-up, 2 (out of the 96) patients died. One patient had a haemorrhagic stroke and died within 3 month period and the other having documented coronary artery disease died suddenly within 1 month. Four patients were lost to follow-up. One patient did not report at 1 month and the other three at 6 month. Data could therefore be obtained for all 96 patients at baseline and before discharge, in 94 patients at 1 month and 90 patients at 6 months. History of diabetes was present in $43(44.8 \%)$ patients, history of hypertension was present in $62(64.6 \%)$ patients, while history of coronary heart disease was present in 28 (29.2\%) patients. Only $19.8 \%$ (19) of the patients had a history of alcohol intake and 6\% (6) patients had positive history of smoking while only $2(2.1 \%)$ patients had history 
of any substance abuse. Presyncope was the most common presenting complaint in 47 (49\%) patients while syncope was present in $25(26 \%)$ patients. Important clinical characteristics of the study population, including detailed information on the pacing indications, implanted cardiac pacing devices and site of pacing, are presented in Table 1. Patients were followed for a mean of 6 months. Around 34\% patients needed single chamber pacemaker (Mainly including Complete heart block with advanced age or financial constraints in whom single chamber-VVI pacemaker was put with all patients having septal lead placement and just few patients of high grade AV block with advanced age or financial constraints had single chamber VVI pacemaker).

\section{Pacemaker lead parameters (Table 2)}

In majority of patients $(66 \%)$ dual chamber pacemaker was implanted with DDD. Single chamber pacemamaker was implanted in $34 \%$ patients with VVI mode

Table 1 Baseline characteristics

\begin{tabular}{|c|c|c|}
\hline & No. of patients & Percentage \\
\hline \multicolumn{3}{|l|}{ Gender } \\
\hline $\mathrm{F}$ & 38 & 39.6 \\
\hline M & 58 & 60.4 \\
\hline Total & 96 & 100.0 \\
\hline \multicolumn{3}{|l|}{ Past history } \\
\hline Diabetes & 43 & 44.8 \\
\hline Hypertension & 62 & 64.6 \\
\hline CAD & 28 & 29.2 \\
\hline \multicolumn{3}{|l|}{ Personal history } \\
\hline Alcohol & 19 & 19.8 \\
\hline Smoking & 6 & 6.3 \\
\hline Others & 2 & 2.1 \\
\hline \multicolumn{3}{|l|}{ Presenting complaints } \\
\hline Non-specific symptoms & 11 & 11.5 \\
\hline Dsypnea & 8 & 8.3 \\
\hline Palpitation & 5 & 5.2 \\
\hline Presyncope & 47 & 49.0 \\
\hline Syncope & 25 & 26.0 \\
\hline \multicolumn{3}{|l|}{ Indication of pacing } \\
\hline CHB (complete heart block) & 62 & 64.6 \\
\hline High degree AV block & 15 & 15.6 \\
\hline SSS (sick sinus syndrome) & 19 & 19.8 \\
\hline Total & 96 & 100.0 \\
\hline \multicolumn{3}{|l|}{ Type of pacemaker } \\
\hline Single chamber & 33 & 34.4 \\
\hline Dual camber & 63 & 65.6 \\
\hline \multicolumn{3}{|l|}{ Lead position } \\
\hline Apical & 8 & 8.3 \\
\hline Septal & 88 & 91.7 \\
\hline
\end{tabular}

and in majority around $92 \%$ patients septal lead was placed. The mean value of resistance of the atrial lead was $535.49 \mathrm{Ohms}$ at the time of pacemaker implantation, $511.34 \mathrm{ohms}$ after 1 month and was $575.13 \mathrm{ohms}$ at the end of 6 months. While the mean value of resistance of the ventricular lead was $595.20 \mathrm{ohms}$ at the time of pacemaker implantation, $565.33 \mathrm{ohms}$ after 1 month and was $628.16 \mathrm{ohms}$ after 6 months. The mean value of threshold of the atrial lead was $1.0 \mathrm{~V}$ at the time of pacemaker implantation, $0.85 \mathrm{~V}$ after 1 month and was $0.77 \mathrm{~V}$ at the end of 6 months. While the mean value of threshold of the ventricular lead was $0.96 \mathrm{~V}$ at the time of pacemaker implantation, $0.85 \mathrm{~V}$ after 1 month and was $0.87 \mathrm{~V}$ after 6 months. The mean value of sensitivity of the atrial lead was $2.71 \mathrm{mV}$ at the time of pacemaker implantation, $2.57 \mathrm{mV}$ after 1 month and was $2.45 \mathrm{mV}$ at the end of 6 months. While the mean value of sensitivity of the ventricular lead was $5.82 \mathrm{mV}$ at the time of pacemaker implantation, $6.24 \mathrm{mV}$ after 1 month and was $6.4 \mathrm{mV}$ after 6 months. Pacing percentage was above $90 \%$ in maximum patients and patient with pacing percentage below $85 \%$ were excluded from study. So this bias was tried to be minimized by excluding low pacing percentage cases which may have altered the results.

\section{QRS duration (Table 2)}

Majority of our patients (92\%) had septal lead placement. The mean QRS duration at the time of admission was $133.18 \mathrm{~ms}$ which had increased significantly to $150.29 \mathrm{~ms}$ before discharge ( $p$ value $<0.0001$ ). At the end of 1 month the mean QRS duration was $140.87 \mathrm{~ms}$ ( $p$ value $=0.001$ ) and increased to $146.03 \mathrm{~ms}$ by the end of 6 months ( $p$ value $<0.0001$ ). Out of the total of 96 patients, an increase of more than $10 \%$ in QRS duration was present in 16 patients at 1 week (out of which $69 \%$ were diabetics, $81 \%$ were hypertensives and had a mean age of 66 years) while in 27 patients at 1 month (out of which $52 \%$ were diabetics, $66 \%$ were hypertensives) and only 39 patients at 6 month (out of which $49 \%$ were diabetics, $64 \%$ were hypertensives).

\section{Echocardiographic parameters (Table 3)}

The mean EF of the patients at the time of admission was 51.47 and showed an insignificant rise to 51.73 ( $p$ value $=0.084$ ) before discharge. By the end of 1 month, the mean EF was 50.10 ( $p$ value $<0.0001)$ and decreased significantly to 47.83 by 6 months $(p$ value $<0.0001)$. Out of the total of 96 patients, 52 patients (54\%) had EF of more than $50 \%$ at baseline (average age of 65 years). These patients had an average decrease of $0.2 \%$ by 1 week, $2.4 \%$ by 1 month and $6.0 \%$ by 6 months in EF as compared to baseline. No patient out of these 52 patients had an EF of less than $50 \%$ during the 6 month follow-up. 
Table 2 Pacemaker parameters and QRS duration

\begin{tabular}{|c|c|c|c|c|c|c|}
\hline & $N$ & Min & Max & Mean & SD & $p$ value \\
\hline \multicolumn{7}{|l|}{ Resistance-A (Ohm) } \\
\hline Before Discharge & 63 & 430.0 & 695.0 & 535.49 & 61.32 & \\
\hline 1 month & 62 & 62.0 & 671.0 & 511.34 & 90.66 & 0.566 \\
\hline 6 month & 60 & 425.0 & 722.0 & 575.13 & 61.43 & 0.108 \\
\hline \multicolumn{7}{|l|}{ Resistance-V (Ohm) } \\
\hline Before Discharge & 96 & 345.0 & 1380.0 & 595.20 & 112.47 & \\
\hline 1 month & 94 & 318.0 & 1335.0 & 565.33 & 111.19 & \\
\hline 6 month & 90 & 355.0 & 1445.0 & 628.16 & 119.59 & 0.7 \\
\hline \multicolumn{7}{|l|}{ Voltage-A (Volt) } \\
\hline Before Discharge & 63 & 0.5 & 4.0 & 1.00 & 0.44 & \\
\hline 1 month & 62 & 0.3 & 1.5 & 0.85 & 0.26 & 0.053 \\
\hline 6 month & 60 & 0.3 & 1.5 & 0.77 & 0.24 & 0.066 \\
\hline \multicolumn{7}{|l|}{ Voltage-V (Volt) } \\
\hline Before Discharge & 96 & 0.3 & 4.0 & 0.96 & 0.39 & \\
\hline 1 month & 94 & 0.3 & 2.0 & 0.85 & 0.27 & 0.1 \\
\hline 6 month & 90 & 0.3 & 6.2 & 0.87 & 0.63 & 0.1 \\
\hline \multicolumn{7}{|l|}{ Sensitivity-A } \\
\hline Before Discharge & 63 & 0.5 & 6.2 & 2.71 & 1.37 & \\
\hline 1 month & 62 & 0.5 & 6.0 & 2.57 & 1.23 & 0.099 \\
\hline 6 month & 60 & 0.5 & 6.5 & 2.45 & 1.24 & 0.085 \\
\hline \multicolumn{7}{|l|}{ Sensitivity-V } \\
\hline Before Discharge & 96 & 0.0 & 15.6 & 5.82 & 5.45 & \\
\hline 1 month & 94 & 0.0 & 15.0 & 6.24 & 5.63 & 0.100 \\
\hline 6 month & 90 & 0.0 & 15.6 & 6.40 & 5.61 & 0.126 \\
\hline \multicolumn{7}{|c|}{ Pacing percentage (\%) } \\
\hline Before Discharge & 96 & 91 & 96 & 93.5 & 2.12 & 0.723 \\
\hline 1 month & 92 & 89 & 94 & 91.5 & 1.32 & 0.542 \\
\hline 6 month & 95 & 92 & 97 & 94.5 & 3.21 & 0.891 \\
\hline \multicolumn{7}{|l|}{ QRS duration (msec) } \\
\hline At admission & 96 & 82.0 & 202.0 & 133.18 & 29.45 & \\
\hline Before Discharge & 96 & 92.0 & 204.0 & 150.29 & 24.74 & 0.000 \\
\hline 1 month & 94 & 84.0 & 188.0 & 140.87 & 20.38 & 0.001 \\
\hline 6 month & 90 & 98.0 & 184.0 & 146.03 & 19.82 & 0.000 \\
\hline
\end{tabular}

Forty-four patients (46\%) had EF of less than or equal to $50 \%$ at baseline (average age of 68 years). These patients had an average decrease of $1.7 \%$ by 1 week, $2.2 \%$ by 1 month and $9.0 \%$ by 6 months in EF from baseline. At 1 month $>5 \%$ decrease in EF as compared to baseline EF was seen in 11 patients (25\%). At 6 month $>5 \%$ decrease in $\mathrm{EF}$ as compared to baseline EF was seen in 29 patients (66\%).

The mean RV stroke volume at the time of admission was $42.34 \mathrm{ml}$ which had increased to $43.86 \mathrm{ml}$ before discharge. At the end of 1 month the mean RV stroke volume was $41.05 \mathrm{ml}$ (decrease of 3\%) and decreased to $38.32 \mathrm{ml}$ (decrease of 9.4\%) by the end of 6 months which shows statistically significant change.
The mean LV stroke volume at the time of admission was $44.58 \mathrm{ml}$ which had increased to $46.29 \mathrm{ml}$ before discharge ( $p$ value $<0.0001)$. At the end of 1 month the mean LV stroke volume was $43.37 \mathrm{ml}$ (decrease of $2.6 \%$ ) and decreased to $41.10 \mathrm{ml}$ (change of $7.6 \%$ ) by the end of 6 months which shows significant change $(p$ value $<0.0001$ ). Cardiac output showed an statistically insignificant change over a period of 6 months.

Left ventricle end systolic diameter and diastolic diameter (LVESD and LVEDD) also show significant changes after period of 1 month and 6 month. Right ventricle end systolic diameter and diastolic diameter (RVESD and RVEDD) showed significant increase at 1 month and continued to increase progressively till 6 months. Practically 
Table 3 Echocardiographic parameters

\begin{tabular}{|c|c|c|c|c|c|c|}
\hline & $N$ & Minimum & Maximum & Mean & SD & $p$ value \\
\hline \multicolumn{7}{|l|}{ LVEF } \\
\hline At admission & 96 & 28.0 & 60.0 & 51.47 & 9.83 & \\
\hline Before discharge & 96 & 28.0 & 60.0 & 51.73 & 9.54 & 0.084 \\
\hline 1 month & 94 & 26.0 & 60.0 & 50.10 & 9.88 & 0.000 \\
\hline 6 month & 90 & 24.0 & 60.0 & 47.83 & 10.41 & 0.000 \\
\hline \multicolumn{7}{|l|}{ RV SV } \\
\hline At admission & 96 & 28.0 & 62.0 & 42.34 & 7.67 & \\
\hline Before discharge & 96 & 23.0 & 66.0 & 43.86 & 8.38 & 0.000 \\
\hline 1 month & 94 & 22.0 & 62.0 & 41.05 & 8.22 & 0.002 \\
\hline 6 month & 90 & 23.0 & 58.0 & 38.32 & 8.08 & 0.000 \\
\hline \multicolumn{7}{|l|}{ LV SV } \\
\hline At admission & 96 & 22.0 & 70.0 & 44.58 & 9.21 & \\
\hline Before discharge & 96 & 25.0 & 75.0 & 46.29 & 8.71 & 0.000 \\
\hline 1 month & 94 & 24.0 & 68.0 & 43.37 & 8.45 & 0.010 \\
\hline 6 month & 90 & 22.0 & 64.0 & 41.10 & 8.73 & 0.000 \\
\hline \multicolumn{7}{|l|}{$\mathrm{CO}$} \\
\hline At admission & 96 & 1.1 & 30.4 & 3.32 & 3.08 & \\
\hline Before discharge & 96 & 2.2 & 34.0 & 3.96 & 3.19 & 0.665 \\
\hline 1 month & 94 & 1.8 & 25.6 & 3.56 & 2.39 & 0.569 \\
\hline 6 month & 90 & 1.7 & 4.8 & 3.09 & 0.69 & 0.461 \\
\hline \multicolumn{7}{|l|}{ LV ESD } \\
\hline At admission & 96 & 12.0 & 49.0 & 31.31 & 7.72 & \\
\hline Before discharge & 96 & 12.0 & 48.0 & 29.80 & 7.48 & 0.000 \\
\hline 1 month & 94 & 12.0 & 50.0 & 32.73 & 7.61 & 0.000 \\
\hline 6 month & 90 & 14.0 & 51.0 & 35.39 & 7.69 & 0.000 \\
\hline \multicolumn{7}{|l|}{ LV EDD } \\
\hline At admission & 96 & 26.0 & 60.0 & 45.60 & 7.19 & \\
\hline Before discharge & 96 & 26.0 & 61.0 & 46.05 & 7.13 & 0.051 \\
\hline 1 month & 94 & 26.0 & 66.0 & 48.96 & 7.49 & 0.000 \\
\hline 6 month & 90 & 30.0 & 68.0 & 52.21 & 7.31 & 0.000 \\
\hline \multicolumn{7}{|l|}{ RVESD } \\
\hline At admission & 96 & 8.0 & 24.0 & 10.30 & 2.68 & \\
\hline Before discharge & 96 & 5.0 & 23.0 & 10.59 & 3.10 & 0.109 \\
\hline 1 month & 94 & 9.0 & 24.0 & 13.13 & 3.29 & 0.000 \\
\hline 6 month & 90 & 9.0 & 28.0 & 16.63 & 4.07 & 0.000 \\
\hline \multicolumn{7}{|l|}{ RVEDD } \\
\hline At admission & 96 & 20.0 & 38.0 & 23.08 & 3.53 & \\
\hline Before discharge & 96 & 20.0 & 38.0 & 24.38 & 3.59 & 0.000 \\
\hline 1 month & 94 & 20.0 & 42.0 & 27.83 & 4.21 & 0.000 \\
\hline 6 month & 90 & 22.0 & 48.0 & 32.66 & 5.53 & 0.000 \\
\hline \multicolumn{7}{|l|}{ LAVI } \\
\hline At admission & 96 & 17.0 & 55.0 & 23.86 & 4.83 & \\
\hline Before discharge & 96 & 13.5 & 57.0 & 24.83 & 5.29 & 0.000 \\
\hline 1 month & 94 & 15.1 & 56.6 & 27.08 & 5.46 & 0.000 \\
\hline 6 month & 90 & 14.7 & 57.5 & 29.50 & 6.18 & 0.000 \\
\hline
\end{tabular}


significant change ( $>5 \%)$ occurs as early as first month in diastolic dimensions of both LV and RV.

Right ventricle myocardial performance index (RVMPI) at the time of admission was 0.60 which showed a gradual increase to 0.61 before discharge. At the end of 1 month the mean RV MPI was 0.66 (an increase of $10 \%$ ) and increased to 0.72 by the end of 6 months ( $p$ value $<0.0001$ for 1 month and 6 month). Mean left ventricle myocardial performance index (LVMPI) also increased similarly, becoming statistically significant by 1 month and 6 months $(p$ value $<0.0001)$. Practically significant increase $(>5 \%)$ in the value of both LVMPI and RVMPI occurs by first month of pacemaker implantation.

The left atrial volume index (LAVI) showed a gradual and progressive increase over a period of 6 months with a change of $4 \%, 13 \%$ and $23 \%$ at first week, first month and 6 months of pacemaker implantation.

The mean TAPSE at the time of admission was $19.0 \mathrm{~mm}$ and $19.42 \mathrm{~mm}$ before discharge $(p$ value $=0.02)$. At the end of 1 month the mean TAPSE was 16.84 (fall of 11\%) and decreased further to 14.58 (fall of $23 \%$ from baseline) by the end of 6 months ( $p$ value $<0.0001$ for 1 month and 6 month).

Our study shows an insignificant decrease in PASP within first week of pacemaker implantation followed by progressive increase over the period of 6 month.

$E / A$ ratio and $E / e^{\prime}$ ratio showed a progressive increase over a period of 6 month suggesting deteriorating LV diastolic function. Practically significant change $(>5 \%)$ in both $E / A$ ratio and $E / e^{\prime}$ ratio occurs as early as first week of pacemaker implantation.

RVS $^{\prime}$ and LVS' showed an increase within the first week of pacemaker implantation followed by a gradual and progressive decrease over the follow-up period of 6 months suggesting the worsening of ventricular systolic functions.

\section{Discussion}

RV pacing has been rigorously evaluated in numerous trials which have shown that it may be associated with a worse clinical outcome like deterioration of LV systolic function, development of heart failure and atrial fibrillation [4-8].

Similar to the results by Zhang et al. [9], our study showed that the deterioration of LV functions was higher in elderly patients and patients having more number of risk factors like both diabetes and hypertension than patients having only hypertension or only diabetes.

The DANPACE study randomized 1415 patients with sinus node dysfunction to AAIR or DDDR pacing and concluded that predictors of development of HF included older age, reduced baseline LVEF, and previous myocardial infarction [10]. Our study also showed that the decrease in EF was more in patients who had prior LV dysfunction, were older in age and had higher number of risk factors like diabetes, hypertension, coronary artery diseases. Studies by Fang et al. [11] and Kiehl et al. [12] have confirmed that pre implant EF is an important predictor for the development of pacemaker induced cardiomyopathy. Tse et al. did not notice any improvement of $\mathrm{LV}$ function during follow-up period for 6 month in their comparative studies of alternate site of pacing but noticed significant improvement in global LV systolic and diastolic function after 18 months [13]. A study conducted by Yu et al. (2009) [14] showed that in patients with normal systolic function, conventional right ventricular apical pacing resulted in adverse left ventricular remodelling and in a reduction in the left ventricular ejection fraction.

Similar to the results by Ebert et al. [15], our study showed that the deterioration in LVEF was gradual and progressive and more in patients who had baseline LV dysfunction. Our findings were in accordance with the study conducted by Sarkar et al. [16] which have shown worsening LV diastolic and systolic functions after pacemaker implantation. Our findings were in accordance with the study by Dwivedi et al. [17] which showed that diastolic dysfunction develops as early as first week after pacemaker implantation. They also suggested that diastolic abnormalities are first to appear which are followed by appearance of systolic abnormalities. Tantengco et al. also studied the left ventricular dysfunction after longterm right ventricular apical pacing and concluded that in young patients requiring long-term RV pacing, alternative sites of ventricular pacing that simulate normal biventricular electrical activation should be explored [18].

Both Ahmad et al. [19] and Schmidt et al. [20] have concluded that RV pacing prolongs QRS duration independent of EF. Majority of our patients (92\%) had septal lead placement. In our study, the worsening of cardiac functions after pacemaker implantation was also evident on ECG as indicated by significant increase in QRS duration over a 6 month follow-up despite septal lead placement. A study conducted by Lee et al. 2014 [21] revealed the best cut-off value of QRS width to be $150 \mathrm{~ms}$ for the prediction of myocardial dyssynchrony. Out of 96 patients, 12 patients had QRS duration of more than $150 \mathrm{~ms}$ at baseline but none of them had symptoms of heart failure. These patients presented with the symptoms of either syncope or presyncope.

There were no incidence of any complications like pocket hematoma, acute perforation, infection, lead dislodgement, erosion, lead fracture or insulation break.

Our study requires further evaluation using modalities like cardiac MRI which have been regarded as gold standard for assessing cardiac functions [22]. In literature, 
various therapeutic options have been suggested in patients with a conventional pacemaker indication. The upgrade to CRT may partially reverse the deleterious effects of RV apical pacing [23, 24]. New pacing strategies and alternative RV pacing sites [25] may prevent the induction of ventricular dyssynchrony and the deterioration of LV function.

\section{Limitations}

The major limitation of our study was small sample size and short follow-up period. Our study requires further evaluation using modalities like cardiac MRI and cardiac strain imaging which have been regarded as gold standard for assessing cardiac functions. Our study also required us to assume a deterioration of $>5 \%$ in the echocardiographic parameters from baseline as a significant change in practical assessment.

\section{Conclusion}

- The mean QRS duration increased significantly by 6 months despite septal lead placement.

- Diastolic parameters like LAVI, $E / A$ and $E / e^{\prime}$ showed a significant increase from baseline by the end of first week.

- By the end of first month, systolic dysfunction of RV sets in with significant change from baseline in parameters like RVMPI, TAPSE and RVS'.

- Significant change in both systolic and diastolic function was present by the end of 6 months without any change in the resting cardiac output.

\footnotetext{
Abbreviations

ECG: Electrocardiogram; LV/RV: Left/right ventricle; LVESD and LVEDD: Left ventricle end systolic diameter/ diastolic diameter; EF: Ejection fraction; LAVI: Left atrial volume index; TAPSE:Tricuspid annular plane systolic excursion; LV/ RV MPI: Left/right ventricle myocardial performance index (Tei Index); MRI: Magnetic resonance imaging; PASP: Pulmonary artery systolic pressure; CRT: Cardiac resynchronisation therapy.
}

\section{Acknowledgements}

We are thankful to supporting staff of critical team. Intensive unit, cath lab, electrophysiology unit for being cooperative in the study.

\section{Authors' contributions}

$\mathrm{HG}$ helped in design of the work, echocardiography and electrophysiology assessment. HIS did acquisition, analysis of data and prepared the study content. NA helped in compiling data, pacemaker implantation, pacemaker parameters assessment and discussion. RT helped in interpretation of data; GSW have drafted the work or substantively revised it. SG helped in statistical data compilation. SA: Helped in calculating data and in noninvasive work. MMS: Helped in revision of study. All authors read and approved the final manuscript.

\section{Funding}

None.

\section{Availability of data and materials}

The datasets used and/or analysed during the current study are available from the corresponding author on reasonable request on email docirfanshahi512@ gmail.com or the corresponding address as given.

\section{Declarations}

Ethics approval and consent to participate

Yes all formal written consents taken (Approved by DMC ethical committeeDMC Ludhiana Punjab with no reference number).

\section{Consent for publication}

The participants and all authors certify that all appropriate written consent forms were given and formally written consents were taken. In the form the patient(s) has/have given his/her/their written consent for his/her/ their images and other clinical information to be reported in the journal. The patient(s) understand that his/her/their name(s) and initials will not be published and due efforts will be made to conceal his/her/their identity, but anonymity cannot be guaranteed. DMC Ethical committee cleared after cross checking the consent forms and format.

\section{Competing interests}

The authors declare that they have no competing interests.

\section{Author details}

'DMC, Ludhiana, Punjab, India. ${ }^{2}$ Grecian Superspeciality Hospital, Mohali 110065, India. ${ }^{3}$ Fortis Escorts Heart Institute, Delhi, India. ${ }^{4}$ Narayana Hrudayalaya Hospital, Ahmedabad, India.

Received: 16 February 2021 Accepted: 6 June 2021

Published online: 25 June 2021

\section{References}

1. Hillock RJ, Mond HG. Pacing the right ventricular outflow tract septum: time to embrace the future. Europace. 2012;14:28-35.

2. Kaye GC, Linker NJ, MarwickTH, et al. Effect of right ventricular pacing lead site on left ventricular function in patients with high-grade atrioventricular block: results of the Protect-Pace study. Eur Heart J. 2015;36(14):856-62

3. Sweeney MO, Hellkamp AS, Ellenbogen KA, et al. Adverse effect of ventricular pacing on heart failure and atrial fibrillation among patients with normal baseline QRS duration in a clinical trial of pacemaker therapy for sinus node dysfunction. Circulation. 2003;107(23):2932-7.

4. Sweeney MO, Prinzen FW. A new paradigm for physiologic ventricular pacing. J Am Coll Cardiol. 2006;47:282-8.

5. Nahlawi M, Waligora M, Spies SM, Bonow RO, Kadish AH, Goldberger J. Left ventricular function during and after right ventricular pacing. J Am Coll Cardiol. 2004;44(9):1883-8.

6. Tops LF, Schalij MJ, Bax JJ. The effects of right ventricular apical pacing on ventricular function and dissyncrhony implications for therapy. J Am Coll Cardiol. 2009:54(9):764-6.

7. Akerström F, Arias MA, Pachón M, Jiménez-López J, Puchol A, Juliá-Calvo $J$. The importance of avoiding unnecessary right ventricular pacing in clinical practice. World J Cardiol. 2013;5(11):410-9.

8. Thambo JB, Bordachar P, Garrigue S, et al. Detrimental ventricular remodeling in patients with congenital complete heart block and chronic right ventricular apical pacing. Circulation. 2004;110(25):3766-72.

9. Zhang $\mathrm{XH}$, $\mathrm{Chen} \mathrm{H}$, Siu CW, et al. New-onset heart failure after permanent right ventricular apical pacing in patients with acquired high-grade atrioventricular block and normal left ventricular function. J Cardiovasc Electrophysiol. 2008;19(2):136-41.

10 Riahi S, Nielsen JC, Hjortshøj S, et al. DANPACE Investigators. Heart failure in patients with sick sinus syndrome treated with single lead atrial or dual-chamber pacing: no association with pacing mode or right ventricular pacing site. Europace. 2012;14:1475-82.

11. Fang F, Chan JY-S, Yip GW-K, et al. Prevalence and determinants of left ventricular systolic dyssynchrony in patients with normal ejection fraction 
received right ventricular apical pacing: a real-time three-dimensional echocardiographic study. Eur J Echocardiogr. 2010;11:109-18.

12. Khurshid S, Epstein AE, Verdino RJ, Lin D, Goldberg LR, Marchlinski FE. C Incidence and predictors of right ventricular pacing-induced cardiomyopathy. Heart Rhythm. 2014;11(9):1619-25.

13 Tse HF, Yu C, Wong KK, et al. Functional abnormalities in patients with permanent RV pacing. The effect of sites of electrical stimulation. J Am Coll Cardiol. 2002;40:1451-548.

14. Yu CM, Chan JY, Zhang Q, Omar R, Yip GW, Hussin A, et al. Biventricular pacing in patients with bradycardia and normal ejection fraction. N Engl J Med. 2009;361(22):2123-34.

15. Ebert M, Jander N, Minners J, Blum T, Doering M. Long-term impact of right ventricular pacing on left ventricular systolic function in pacemaker recipients with preserved ejection fraction: results from a large singlecenter registry. J Am Heart Assoc. 2016;5(7):e003485.

16. Sarkar NC, Tilkar M, Jain S, Mondal S, Sarkar P, Modi N. Evaluation of long term effect of RV apical pacing on global LV function by echocardiography. J Clin Diagn Res. 2016;10(3):3-6.

17. Dwivedi SK, Bansal S, Puri A, et al. Diastolic and systolic right ventricular dysfunction precedes left ventricular dysfunction in patients paced from right ventricular apex. Indian Pacing Electrophysiol J. 2006;6(3):142-52.

18 Tantengco MV, Thomas RL, Karpawich PP. Left ventricular dysfunction after long-term right ventricular apical pacing in the young. J Am Coll Cardiol. 2001;37(8):2093-100.

19. Ahmed M, Gorcsan J, Marek J, et al. Right ventricular apical pacinginduced left ventricular dyssynchrony is associated with a subsequent decline in ejection fraction. Heart Rhythm. 2014;11(4):602-8.
20. Schmidt M, Brömsen J, Herholz C, et al. Evidence of left ventricular dyssyncrhony resulting from right ventricular pacing in patients with severely depressed left ventricular ejection fraction. Europace. 2007;9(1):34-40.

21. Lee KH, Cho JG, Park HW, Yoon NS. QRS morphology and ventricular dyssynchrony in patients with chronic right ventricular pacing. Int J Cardiol. 2014;176(3):962-8.

22. Duarte R, Fernandez G. Assessment of left ventricular diastolic function by MR: why, how and when. Insights Imaging. 2010;1 (3):183-92.

23. Ansalone G, Giannantoni P, Ricci R, Trambaiolo P, Fedele F, Santini M. Doppler myocardial imaging to evaluate the effectiveness of pacing sites in patients receiving biventricular pacing. J Am Coll Cardiol. 2002;39(3):489-99.

24. Garrigue S, Jaïs P, Espil G, et al. Comparison of chronic biventricular pacing between epicardial and endocardial left ventricular stimulation using Doppler tissue imaging in patients with heart failure. Am J Cardiol. 2001;88(8):858-62.

25 Shimony A, Eisenberg MJ, Filion KB, Amit G. Beneficial effects of right ventricular non-apical vs. apical pacing: a systematic review and metaanalysis of randomized-controlled trials. Europace. 2012;14(1):81-91.

\section{Publisher's Note}

Springer Nature remains neutral with regard to jurisdictional claims in published maps and institutional affiliations.
Ready to submit your research? Choose BMC and benefit from:

- fast, convenient online submission

- thorough peer review by experienced researchers in your field

- rapid publication on acceptance

- support for research data, including large and complex data types

- gold Open Access which fosters wider collaboration and increased citations

- maximum visibility for your research: over 100M website views per year

At BMC, research is always in progress.

Learn more biomedcentral.com/submissions 